\title{
An Empirical Assessment of SMEs' Financing Risks in Ghana
}

\author{
Safia Wemah ${ }^{1}$ Mathias Akamba ${ }^{2}$ Luu Yin $^{3 *}$ \\ 1.Finance Office, University for Development Studies, P. O .Box TL1350, Tamale, Ghana \\ 2.Faculty of Mathematical Sciences, Department of Statistics, CKT- University of Technology and Applied \\ Sciences (CKT-UTAS), P.O. Box NV24. Navrongo, Ghana \\ 3.Faculty of Mathematical Sciences, Department of Mathematics, CKT- University of Technology and Applied \\ Sciences (CKT-UTAS), P.O. Box NV24, Navrongo, Ghana
}

\begin{abstract}
As complex challenges continue to hamper the rapid development of Small and Medium sized Enterprises (SME), it is important that these challenges are identified and mitigated. The major issue identified is shortage of debt financing. The difficulties that SMEs experience stem from several sources. The financial institutions hardly provide any financial products and services for SMEs. The lack of appropriate financing mechanisms emanates from a variety of reasons, such as regulatory rigidities, gaps in the legal framework, cost of credit and lack of trust between financial institutions and SMEs'. The difficulty in obtaining debt financing by SMEs' is compounded by the lack of transparency in the socio-economic and business environment. This paper presents the findings of an empirical assessment on SMEs, it investigated on how risk associated with access to finance, inflation, customer services, rain failure, fertilizer and veterinary services affect the Agro processing, Agriculture, Trade and Textile industries and the perceptions of financial institutions on providing financing to SMEs. The results indicated that access to finance and inflation are the most critical risks and cut across all industries. A greater proportion of the financial institutions (68.75\%) attributed default in loan repayment and misapplications of loans by SMEs as reasons for the SMEs not attracting loans from banks. The rest (31.25\%) said mismanagement and lack of managerial skills by SMEs. These findings provide an important baseline data for further research and industry collaborations exploring education with debt financing potentials for SMEs by financial institutions.
\end{abstract}

Keywords: Small and medium sized enterprises (SMEs), Financing, financial institution and Risk.

DOI: $10.7176 /$ RJFA/11-22-02

Publication date: November $30^{\text {th }} 2020$

\subsection{INTRODUCTION}

Small and medium scale enterprises (SMEs) play an important role in the economy of every nation, in terms of employment and their contribution to national wealth (Turner, Ledwith and Kelly, 2009). Historical facts show that prior to the late 19th century, cottage industries, mostly small and medium scale businesses controlled the economy of Europe. The industrial revolution changed the status quo and introduced mass production. For small business, looking for funding can be quite a herculean experience. SMEs are also the engine for future growth in every developing economy (Ayyagari, Demirgüç-Kunt, and Maksimovic, 2014). One major problem faced by businesses in Ghana is insufficient financing of which SMEs are not left out and this brings about reasons to empirically assess the degree of prevalence of such other risks and the reasons and perceptions on the supply side by the banks.

According to Mensah (2004) data from the Registrar General Department indicates that 90 percent of companies registered in Ghana are micro, small and medium enterprises. He also indicated that the Ministry of Trade and Industry (MOTI), in 1998 estimated that the Ghanaian private sector consists of approximately 80,000 registered limited companies and 220,000 registered partnerships.

It is traditionally perceived that financial institutions in Ghana have been cautious with lending to SME groups because of high default rates and other risks associated with the sector. Few banks have, however, developed an explicit policy for SME target groups taking the particular requirements and needs into consideration, e.g. developing earmarked financial products and appropriate credit management systems. Only few banks have SME specific loan products, and many of these are donor funded (World Bank. 2006). Few banking institutions have SME desks or departments. For the others, lending to micro and small businesses is simply transacted by credit officers from corporate finance departments of the bank who generally apply the same appraisal and lending principles for larger organizations to SMEs (Abhor and Quartey 2010). None of the commercial banks have any specialized training for credit officers in proven SME lending techniques, and most credit officers do not have any prior SME specific experience. Aside from all these many interventions, SMEs still suffer a persistent financing gap (Aryeetey et al, 1994).

Generally, the objective of the study is to evaluate the risk of cash flow and profitability in small and medium scale enterprises (SME's) and identify the banks perception on providing financing to SMEs in the Kassena Nankana municipality of the Upper East Region of Ghana. We specifically: Identified the various risks of SMEs; Evaluated the risks associated with financing the SMEs; and Assessed the Banks perceptions on providing 
financing to SMEs.

\subsection{LITERATURE REVIEW}

\subsection{The various risks of SMEs.}

Risk identification in SMEs operations is important and requires proper steps in identifying them. According to Marcelino-Sádada, Perez-Ezcurdia, Echeverria, and Villanueva (2014) risk identification may be decisive in SME management and that more risk should be carefully identified and analysed. Risk identification in SMEs may be hindered by SMEs employee's limited knowledge of risk. In their case study, they concluded that a pre-condition of effective and comprehensive risk identification in SME, would be building risk management capacity in their employees. The limited finance was raised by Falker and Hiebl (2014): they said larger enterprises faced various risks not only SMEs whose survival is more easily threatened because of their smaller set of both financial and non-financial resources. The European Union (EU) Member States traditionally had their own definition of what constitutes an SME, for example, the traditional definition in Germany had a limit of 500 employees, while in Belgium it could have been 100 (European Commission, 2003). But now, the EU has standardize the concept. Its current definition categorizes companies with fewer than 50 employees as "small", and those with fewer than 250 as "medium"(European Commission, 2003). By contrast, in the United States, where small business is defined by the number of employees, of less than 100 employees, while medium-sized business often refers to those with less than 500 employees. However, the most widely used American definition of micro-business by the number of employees is the same as that of European Union (ie. less than 10 employees) (Petrakis and Kostis, 2012).

The statistical definition of SMEs varies by countries, and is usually based on the number of employees or the value of assets. The lower limit for small - scale enterprises is usually set at 5 to 10 workers and the upper limit at 50-100 workers. The upper limit for medium scale enterprises is usually set between 100 and 250 employees. Since statistical definitions vary, it is difficult to compare size distributions across countries. However, one should not be overly concern about the lack of consistency in employment-based of SMEs since it is misleading (Rajeevan, Suphey and Rajasekar, 2015).

For some time now, Africa's overall economic performance, with few exceptions, has not been impressive. The results have been mixed, sometimes with performance showing improvement, and at another times going down. High population growth, declining per capita income, crushing external debt, fragile democracy and a political climate characterized by civil unrest and strife have not provided an environment conducive to development (Asmelash, 2002).

One of such is the independent fund manager called the SME Manager Limited (SML), which is an advisory company established by Africa Capital Alliance (ACA) to promote SME sector-led investment in Nigeria by making equity investment in Nigerian SMEs. Also, available are: the bank of industry, the new partnership for Africa Development (NEPAD) initiative and the Africa Growth and opportunity Act AGOA, of the United States (Fadeyibi, 2009).

Africa's ability to break out of its current non-impressive economic performance would, to a large extent, depend on its ability to harness the entrepreneurial potential visible in its streets, market places and small and medium scale enterprises (Asmelash, 2002). In spite of repeated public announcements about their assumed importance as instruments of development, SMEs in many Africa countries enjoy a lukewarm support. They lack effective organization and knowledge of modern management techniques.

Organizations created to promote SMEs are not sufficiently prepared for the task and the interface with policy-makers leaves much to be desired.

The majority of studies on banking and financing for SMEs have focused on the US and other developed countries such as Germany, Italy and Japan (Berger, Rosen and Udell 2007) whiles the demand side of debt financing and the supply side of developing countries has not been studied. Ikasari, Sumransat, Eko, and Kusumastuti, (2016) noted that the widely accepted perspective to assess small business' access to finance is that of economic view. This is due to the effect it has on every economy as an engine of economic growth. SMEs are noted for their contributions to economic development (Abhor and Quartey 2010; Ayyagari, Demirgüç-Kunt, and Maksimovic, 2014; and Rajeevan, Suphey and Rajasekar 2015). There is no universally accepted definition of SMEs in Africa. Even definitions in other countries lack uniformity and reflect the relative development of the respective economies (Beyene, 2000).

Most businesses in Ghana fall within the category of Micro, Small and Medium Enterprises (MSMEs), and with an employment capacity of close to $70 \%$ of the Ghanaian labour force. They range from farming activities, agri-businesses, light manufacturing, art and craft, textiles and garments, tourism, financial services, construction business, carpentry, just to mention a few. But due to lack of adequate attention and support, the growth of these MSMEs has suffered a great deal over the past decades, resulting in the shifting of focus from entrepreneurship to a proliferation of petty trading nationwide (World Bank, 2006).

The risk facing SME's in many developing countries are monumental. The most worrying among these risks is debt financing. Most new small business enterprises are not attractive prospects for banks, as they want to 
minimize their risk profile. Small enterprises in developing countries typically cite lack of access to finance as a major constraint on their operations. This lack of access is often associated with financial policies and bank practices that make it hard for banks to cover the high costs and risks involved in lending to small firms (Aryeetey. et. al, 1994)

However, he did found that many of the successful small enterprises had some access to bank finance. May had also noted that some had some form of external finance, such as customers' advances and suppliers' credit in addition to the bank finance.

\subsection{Risks associated with SMEs financing and a comparative analysis of these risk.}

Risk management is the identification, assessment, and prioritization of risks followed by coordinated and economical application of resources to minimize, monitor, and control the probability and/or impact of unfortunate events (Hubbard, 2009). Risks can come from uncertainty in financial markets, project failures, legal liabilities, credit risk, accidents, natural causes and disasters as well as deliberate attacks from an adversary (ISO/IEC Guide 2009:73).

The field of credit risk modelling has developed rapidly over the past few years to become a key component in the risk management systems at financial institutions (Altman et al, 1997). In fact, several financial institutions and consulting firms are actively marketing their credit risk models to other institutions. In essence, such models permit the user to measure the credit risk present in their asset portfolios. Financial risk management refers to the practices used by corporate finance managers and accountants to limit and control uncertainty in the firm's total portfolio. Financial risk management aims to minimize the risk of loss from unexpected changes in the prices of currencies, interest rates, commodities, and equities (Alexander et al, 2005).

The transaction of SMEs' loans is high because the loans they qualify for are normally smaller amounts. This discourages the banks that are even ready to offer them the loans. This is because banking credit is a typical scale economy such that the larger the loan amount, the smaller the unit transaction cost (Duan, Xiaojie and Hongbo, 2009).

SMEs faced greater risks in operation. SMEs usually operate in a short period. The probability of exiting from the market is high, which increases the risks of banks objectively. It is estimated that nearly $23.7 \%$ of small enterprises disappear in two years and nearly $52.7 \%$ of small enterprises exit the market in four years due to business failure, bankrupt, or other reasons (Huang and Zhang, 2007).

Most SMEs do not have sufficient assets that can be used as collateral for their loans. Because the cash inflows of these businesses are not directly through the banks require effective guaranties supported by valuable assets that can be relied upon if the borrower defaults. Thus banks will not offer loans to SMEs without effective guarantee even if they feel optimistic about the SME's development. Many SMEs adopt mutual private guaranties in order to obtain capitals. The advantages are lower requirements, easy operation, and wide adaptation (Wenyan and Zonghua, 2005).

The strategies to manage risk include transferring the risk to another party, avoiding the risk, reducing the frequency of occurrence and/or the negative effect of the risk, and accepting some or all of the consequences of a particular risk. Certain aspects of the risk management standards have come under criticism for having no measurable improvement on risk even though the confidence in estimates and decisions increase (Hubbard, 2009).

Credit risk is defined as the degree of value fluctuations in debt instruments and derivatives due to changes in the underlying credit quality of borrowers and counterparties.

\subsection{Identified Banks perceptions on providing financing to SMEs.}

Improving the finance of small and medium sized enterprises is crucial in fostering entrepreneurship, competition, innovation and growth in Ghana. Access to sufficient capital to grow and further develop their activity is a difficulty faced by many Ghanaian SMEs. This situation is compounded by the difficulties in accessing finance as SME financing is considered by many financial providers as a high risk activity that generates high transaction costs and/or low returns on investment. Moreover, SMEs need to meet the challenges of adapting to the changing financial environment and to the increasing complexity and extent of financial information required by financial institutions (Adu, 2007). An SME survey, conducted in March-June 2006 by the Ministry of Trade and Industry, Private Sector Development and President Special Initiatives (MOTI/PSD/PSI) and Japan International Cooperation Agency (JICA) indicated that only $21.6 \%$ of SMEs have ever used financial support from financial intermediary or government agency, and that $66.3 \%$ have never received information on the financial sources. The reasons for this include;

1) Unavailability of user-friendly SME financing products

2) Inability of applicant to meet the requirements of the SME Financial Institutions (FIs)

3) Insufficient awareness of the available SME financial schemes

4) Lack of ability or willingness to access to financial information. 


\subsection{RESEARCH METHODOLOGIES}

3.1 The Research was built on the Mixed Research Design. Both qualitative and quantitative data were collected from SMEs and Financial institutions in the Navrongo municipality. The target population of the study included all financial institutions and SMEs available in the Municipality. Enterprises that were sampled to participate in the study included; Pito ${ }^{1}$ brewers, smock ${ }^{2}$ weavers, tailors, carpenters, food vendors, drinking spots, roasted meat sellers, filling stations, farmers and fish mongers. These enterprises were categorised into four groups as; Agriculture, Agro processing, Trade, and Textile. 15 respondents were randomly selected from each category making a total of 60 and 8 respondents from the financial institutions. The SMEs were selected using stratified simple random sampling while the simple random sampling techniques were used for the respondents from the financial institutions. The data were analysed using Pair-wise ranking, Chi square, and other descriptive statistics.

\subsection{PRESENTATION OF RESULTS AND DISCUSSIONS}

This section of the report presents the research findings based on the primary data analysed. The presentation directly addresses the research objectives of the study and flows as follows: (a) Identify the various risks SMEs are exposed to; (b) Evaluate the risks associated with SMEs financing and a comparative analysis of these risks. (c) Assess the Banks perceptions on providing financing to SMEs.

\subsection{RISK EXPOSURES OF SMES}

\subsubsection{RISK ASSOCIATED WITH TRADING}

The various risks obtained from the data on traders included access to finance, customer service and inflation. These risks are coded as follows; Access to finance (AF), Customer services (CS) and Inflation (I). These were ranked using the pair-wise ranking technique so as to determine the entrepreneurs' perceived most critical risk of the industry.

Table 1.0: pair-wise ranking: Risks of Trading

\begin{tabular}{|l|l|l|l|}
\hline & AF & CS & I \\
\hline AF & - & AF & AF \\
\hline CS & & & CS \\
\hline I & & & - \\
\hline
\end{tabular}

Source: Field Data (2019)

From tables 1.0 and 1.1, entrepreneurs ranked access to finance as their most critical risk threatening the survival and progress of their businesses in the Municipality. Except for one, all the sampled entrepreneurs unanimously lamented that their effort to obtain loans from the banks were in vain. The exempted entrepreneur although benefited from Bank loan was never given another opportunity even though his company, filing station, never defaulted in any of the repayment instalments. These justify the crucial nature of financing problems for SMEs. The study indicates that traders' inability to obtain the needed finance to sufficiently capitalize the operations, i.e. to order goods in economic quantities, disfranchised them from competitive pricing and better customer services.

Customer service is the second major risk that affects the industry. The traders are not able to meet their clients demand for many varieties of their products at competitive prices. This could be attributed to insufficient working capital to procure their inventories in economic quantities which will support competitive pricing. This deficiency makes the attraction, retention and maintenance of customers difficult for most traders.

Inflation which causes prices of commodities to rise is also a risk to the industry. Most are caught unaware by ground price increases. They unknowingly sell their goods at the previous prices only to realize a rise in prices when restocking. Where there is no information asymmetry and traders respond to price increases, it also sores the already perceived higher price index. Although the risk factors favour the smarter traders, majority fall victims, leading to a decrease in the real value of their liquid capital.

\subsubsection{RISKS ASSOCIATED WITH AGRICULTURAL INDUSTRY}

The small and medium scale commercial Agriculturists in the District are exposed to many risky factors in their various activities. During the risk assessment survey, the sampled entrepreneurs listed the following perils as the risk factors they are exposed to; access to finance (AF), rains failure (RF), scarce labour on school days (L), fertilizer (FZ) and veterinary services (VS). Respondents were assisted to rank the risk factors to determine the most critical down to the least critical risk exposure using the pair-wise ranking tool.

\footnotetext{
${ }^{1}$ Pito is a local alcoholic beverage brewed using malt from millet or guinea-corn.

${ }^{2}$ Smock is a traditional garment endogenously woven with cotton thread.
} 
Table 2.0: pair-wise ranking:

Risks of Agriculture

\begin{tabular}{|l|l|l|l|l|l|}
\hline & AF & RF & L & FZ & VS \\
\hline AF & - & AF & AF & AF & AF \\
\hline RF & & - & L & FZ & VS \\
\hline L & & & - & L & L \\
\hline FZ & & & & - & FZ \\
\hline VS & & & & & - \\
\hline
\end{tabular}

Source: Field Data (2019)

From table 2.1, access to finance was ranked first, indicating that it is the most critical risk the farmers are exposure to and actually suffer most. Rain Failure (RF) which is a pure loss peril and fundamental in character is among the least risk factors.

The study indicates that upon the various risks associated with agriculture activities in the District, access to finance is the most critical and therefore is ranked first. Farmers need for labour during school days is another risk. Their wards who serve as their source of labour are mostly in school during the early part of the farming season and the cost of hired labour is mostly expensive and this has been one of the high ranking risks to the farmers. The prevalence of insufficient funding could have been mitigated by some free farm hands from the family members especially the male youth who, for the sake of education, have migrated to other towns. The tilling of the crop farms and sending the animals out for feeding are then left in the hands of the few adults and aged parents at home. This impedes farm expansion and increase productivity. Some farmers have, out of frustration due to persistent loss of livestock and stealing by external or hired care-takers, quit the business. The aged but hard to quit entrepreneurs have equally reverted to subsistence farming at the expense of commercial farming. This unfortunate situation has contributed to increase the nation's import bill for food and meat although the entire country is agrarian and suitable for all kinds of farming.

Fertilizer application is solely associated with crop farming. It was mentioned as a risk because aside from it being expensive, it is mostly available at the wrong time. Farmers who can afford it do not get it in good time to fertilize their farms and so suffer low yield. It is ranked equally to labour supply as the 2 nd highest risk in the industry. Veterinary services were rated second but last to rainfall failure by the entrepreneurs. The inconsistency of veterinary service delivery to livestock farmers renders it a risk. Farmers' inability to access their services as and when needed cause loss of animals through preventable illnesses. The risk associated with the service is probably rated low because the study area has a veterinary clinic with a qualified veterinary doctor supported by three technical officers. Nonetheless farmers complained they sometimes do not meet any of these officers in the clinic. Rainfall failure which affects farmers in growing their crops and livestock from getting weeds to feed on was the least rated risk. The ICOUR (Irrigation Company of Upper Region) irrigation farm lands could be the reason why the risk of rain failure is not significant risk in the study area.

\subsubsection{RISK ASSOCIATED WITH TEXTILE INDUSTRY}

The textile industries captured in the study include smock material weaving, smock sewing and other dress making. Risks identified in this industry include the following; bad debt (BD) where a customer after taking his/her cloth and making part payment will not pay the rest of the money, customer relation (CR) problems often occurs when customer complains of styles made for them and may sometimes refuse to take their clothes, access to finance (AF) occurs when the entrepreneurs are denied loans by their banks and so hardly expand their business, and credit (C) is yet another risk to the players in the industry. This occurs when customers want the services of the industry on credit which when care is not taken, ends up as bad debt. These risk factors were captured respectively into the pair-wise ranking tables 3 and 3.1, using the following variables; $\mathrm{BD}, \mathrm{CR}, \mathrm{AF}$ and $\mathrm{C}$.

Table 3.0: pair-wise ranking:

Risks of Textiles

\begin{tabular}{|l|l|l|l|l|}
\hline & AF & BD & CR & C \\
\hline AF & - & AF & AF & AF \\
\hline BD & & - & BD & BD \\
\hline CR & & & - & CR \\
\hline C & & & & - \\
\hline
\end{tabular}

Table 3.1: Score of ranking

Textile risks

\begin{tabular}{|l|l|}
\hline RISK & SCORE \\
\hline AF & $\mathbf{3}$ \\
\hline BD & $\mathbf{2}$ \\
\hline CR & $\mathbf{1}$ \\
\hline C & $\mathbf{0}$ \\
\hline
\end{tabular}

The textile industry, like the previous ones, ranked access to finance first. The lack of financing to buy raw materials in order to expand their businesses was very critical across the three sampled units of the industry. This was followed by bad debt which is caused by customers making part payment and failing to pay the remaining of their charge after receiving their dresses. Although this was prevalent among all the players of the textile sector, it was very common among the tailors. Aside from these, rejection of clothes by customers after it had been sewn was identified as another area of bad debt (financial risk/loss) peculiar to the tailors and material weavers in the 
industry. Sometimes new ones are made to replace the rejected ones at the cost of the weaver/tailor. This arises in cases where the dress is sewn or the material woven based on a description by the customer rather than by sample. Service on credit which was ranked last is due to the fact that most members of the industry do not encourage credit transaction. They won't give out cloths or materials on credit or even if part of the fee or cost is paid.

\subsubsection{RISK ASSOCIATED WITH AGRO PROCESSING INDUSTRY}

Agro-processing industry encompasses all operations from the stage of harvest till the when the product get to the end users in the desire form. Businesses captured under this industry include food vendors, roasted meat sellers and pito brewers. The agro processing industries in the district are exposed to many risks factors in their activities. Some of the risks identified were health hazards (HH), unfinished products (UP), customer expectations (CE), access to finance (AF) and low patronage (P).

Table 4.0: pair-wise ranking:

Risks of Agro Processing

\begin{tabular}{|l|l|l|l|l|l|}
\hline & AF & HH & UP & CE & P \\
\hline AF & - & AF & AF & AF & AF \\
\hline HH & & - & HH & HH & P \\
\hline UP & & & - & CE & UP \\
\hline CE & & & & - & CE \\
\hline P & & & & & - \\
\hline
\end{tabular}

Source: Field Data (2019)

As per tables 4 and 4.1, access to finance was identified and ranked the most critical risk to the agro processing industry in the district and therefore is ranked first. Health problems and customer expectations were ranked equally at 2. Fire wood or charred wood are mostly used in the activities of the agro processors. The people working in the industry are exposed to smoke and the risks of burns by the fire and sometimes fall ill as a result. Customers expect more from the industry but the various challenges the operators faced, inhibited them from meeting such expectations. These mostly lead to high clientele turnover and subsequently low profitable customers. Low patronage was ranked equally with unfinished product as $3^{\text {rd }}$. The low patronage leads to the unfinished products normally getting spoilt and thus causing losses to the industry players especially during unfavourable weather conditions. Inflation was not so critical probably because it is only seasonally influenced. Again it is possible for the entrepreneurs in the industry to control this peril by stocking their raw materials appropriately after harvest.

\subsection{COMPARATIVE ANALYSIS OF RISKS BETWEEN INDUSTRIES}

This compares the risks within the various industries with each of the others. Pair-wise ranking is used and the most critical risks within any two industries are identified. The analysis unavoidably generated some fluctuations in the results. The score of some risks in the various industries either registered some decreases or remained constant, while others always score highest to show how critical they are to SME's.

\subsubsection{RISKS OF TRADE AND AGRICULTURE}

Risks of traders include; access to finance (AF), customer services (CS) and inflation (I). Risks of agriculture include; access to finance (AF), rains failure (RF), scarce labour on school days (L), fertilizer (FZ) and veterinary services (VS).

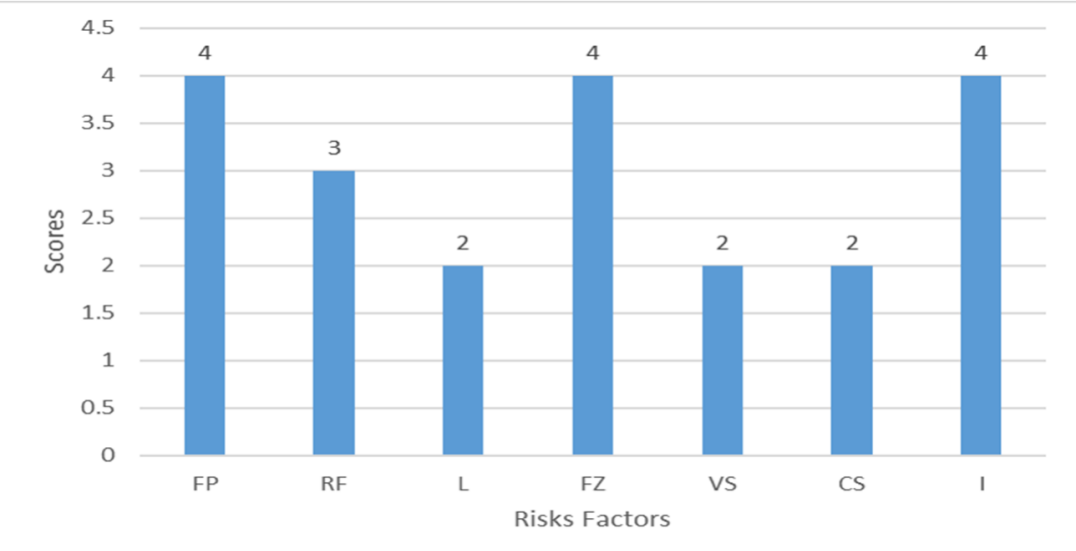

Figure 4.1: Chart of ranked risks of Trading and Agriculture

Source: Field survey (2019)

Applying the same pair-wise ranking approach, the rankings of the combined perils listed by both groups of 
entrepreneurs generated the scores in figure 4.1. Three risk factors - financial problem (FP), high/expensive fertilizer cost, and inflation are of equal ranking and topped the rest.

Although fertilizer and inflation were ranked $3^{\text {rd }}$ in Agriculture and trade respectively, they were ranked first and equivalent to access to finance in this comparative ranking. Thus entrepreneurs identified these risk factors to have about equal and greater adverse effects on their businesses.

\subsubsection{RISKS OF TRADERS AND TEXTILE}

Risks of traders include; access to finance (AF), customer services (CS) and inflation (I) and risks of textile include; access to finance (AF), bad debt (BD), customer relation (CR), service on credit (C). The entrepreneurs pair-wise ranking of these perils generated the following.

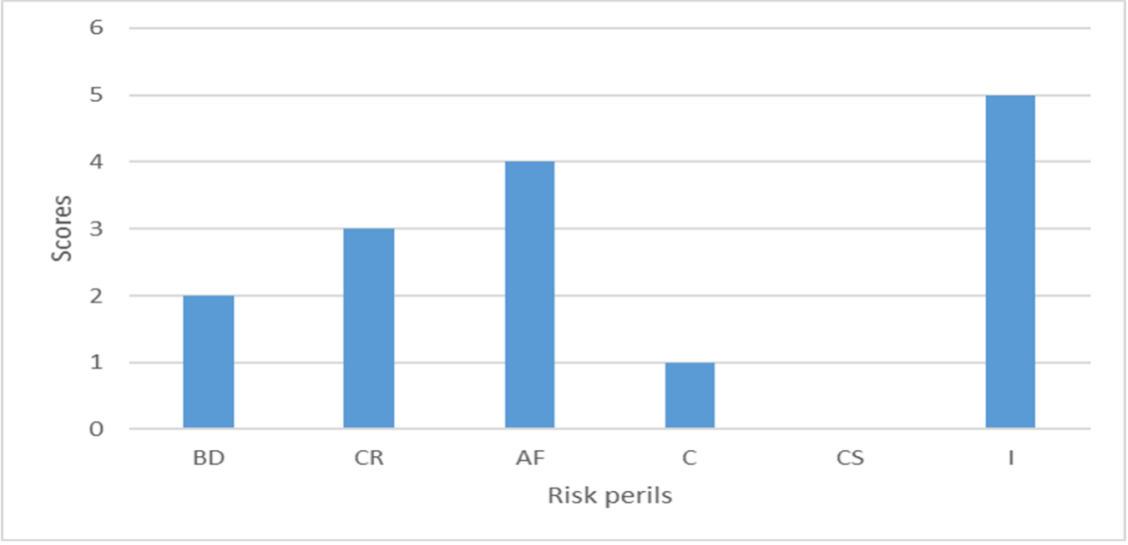

FIGURE 4.2: Chart of ranked Risks of trading and textile businesses

Source: Field Data (2019)

Although the rankings of the traders in tables 1 and 1.1, had inflation to be the least risk factor, and the textile industry did not even have inflation as a risk factor, when the trading and textiles strata entrepreneurs were to rank their combined perils, inflation was ranked first over access to finance that ranked first in the individual industries which means this exogenous risk factor (inflation) causes much loss to the industries.

\subsubsection{RISKS OF TRADING AND AGRO-PROCESSING}

The individual perils identified by the two categories include the following: risks of traders- access to finance (AF), customer service (CS) and inflation (I); and the risks of agro processing- health problems (HP), unfinished products (UP), customer relation (CR), access to finance (AF) and patronage (P).

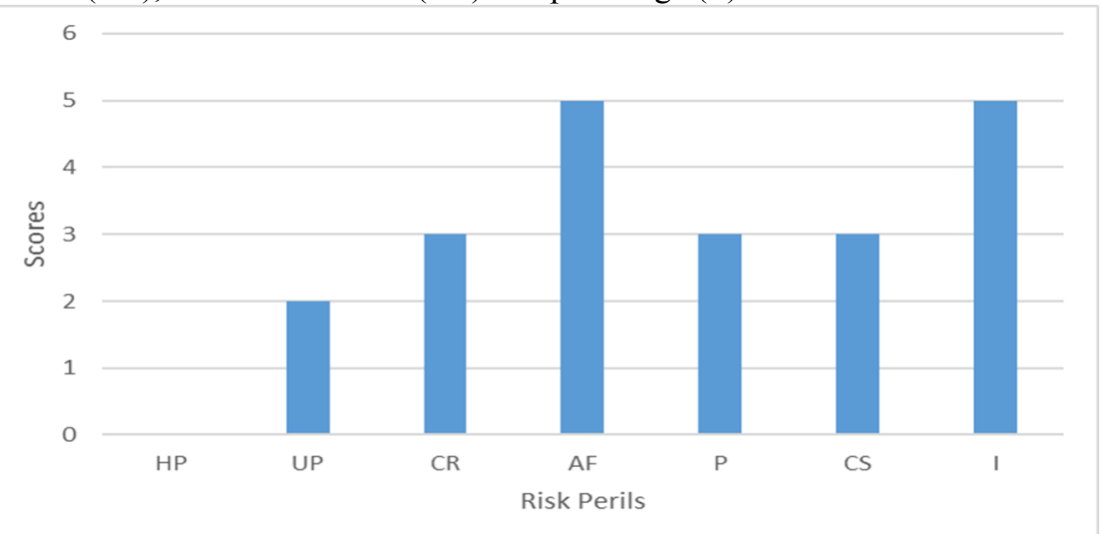

FIGURE 4.3: Chart of ranked Risks of Trading and Agro Processing businesses Source: Field Data (2019)

Figure 3 reveals an equal rank for access to finance and inflation in a comparative analysis between traders and agro processing as the most critical risks of both industries. Health problem was unfortunately ranked very irrelevant by both groups of entrepreneurs.

From figures 4.1 to figure 4.3 it is clear that inflation is a dominant peril acknowledged by all the respondents as being critical to their operation. However, from their individual exposures identifications, only the trading group identified as a peril. This means there are other perils that the respondents ignored or could not remember to list /identify during the preliminary interview sessions.

\subsubsection{RISKS OF AGRICULTURE AND TEXTILES}

The risks associated with agriculture include; access to finance (AF), rains failure (RF), scarce labour on school days (L), fertilizer (FZ) and veterinary services (VS) whilst that of the textile industry on the other hand include; bad debt (BD), customer relation (CR), access to finance (AF) and credit (C). 


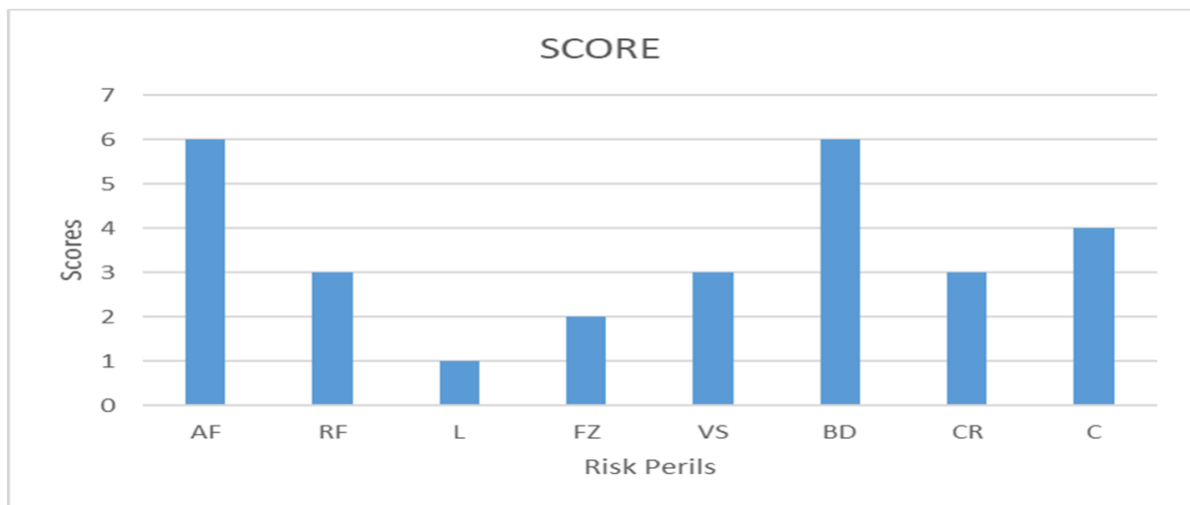

FIGURE 4.4: Chart of ranked Risks of Agriculture and Textiles businesses Source: Field Data (2019)

Bad debt which was ranked second in the textiles industry has moved upwards to gain an equal ranking with access to finance in the comparative analysis between agriculture and textile as reveal in Figure 4 . In the same manner, labour (L) which was also second priority peril in agriculture has become least risk factor under the combined ranking with textiles. Rainfall and veterinary services which were ranked last and second but last in agriculture have also gained relevance under the combined ranking with textiles.

\subsubsection{RISKS OF AGRICULTURE AND AGRO-PROCESSING}

Risks of agriculture industry include; access to finance (AF), rains failure (RF), scarce labour on school days(L), fertilizer(FZ) and veterinary services(VS). The risks of the agro-processing include; health problems(HP), unfinished products(UP), customer relation(CR), access to finance(AF) and patronage(P).

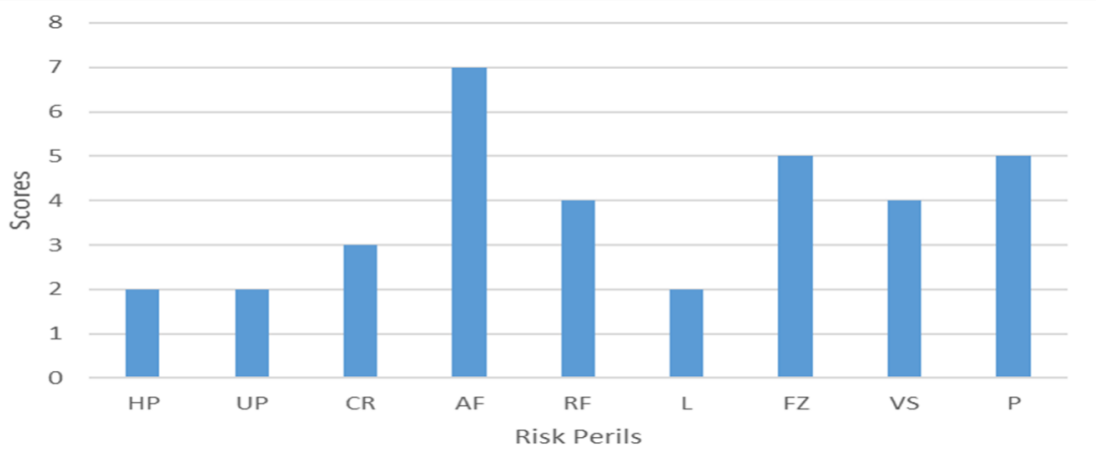

FIGURE 4.5: Chart of ranked Risks of Agriculture and Agro Processing businesses Source: Field Data (2019)

Figure 4.5 reveals that fertilizer and patronage which were ranked second and forth in Agriculture and agro processing respectively, have maintained the same second position in the comparative analysis between the two strata - agriculture and agro processing.

\subsubsection{RISKS OF AGRO PROCESSING AND TEXTILES}

The various risks obtained under agro-processing include; health problems (HP), unfinished products (UP), customer relation (CR), access to finance (AF) and patronage (P). Risks of textiles include; bad debt (BD), customer relation $(\mathrm{CR})$, access to finance $(\mathrm{AF})$ and credit(C).

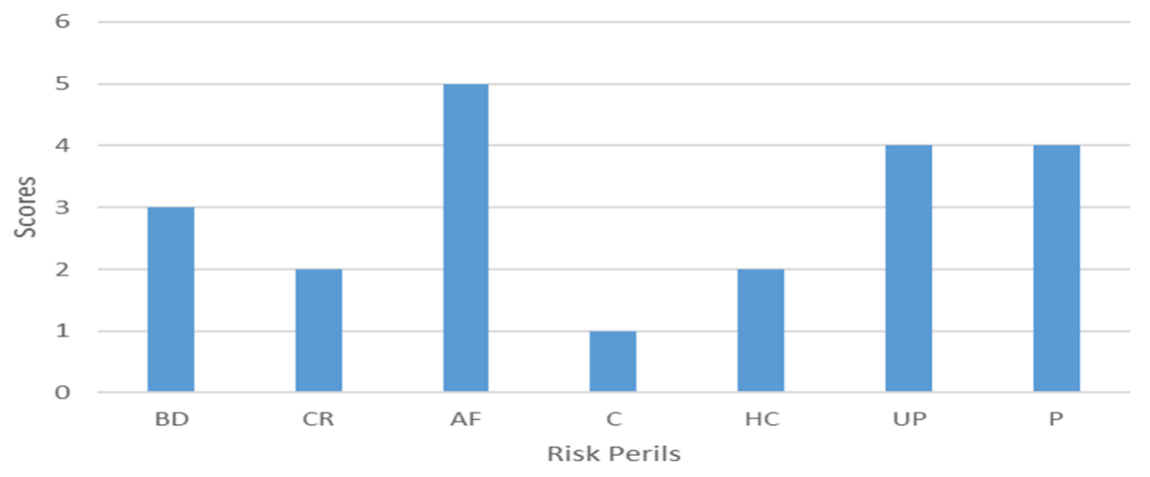

FIGURE 4.6: Chart of ranked Risks of Textiles and Agro Processing businesses Source: Field Data (2019) 
Figure 4.6 reveals that access to finance maintained its position at the first ranked while patronage and unfinished products are ranked equally as in their prospective industry.

\subsection{EXPLORATORY ANALYSIS OF ALL INDUSTRIES}

The risks obtained from all the industries captured in the study include; access to finance (AF), customer service (CS), inflation (I), rain failure (RF), scarce labour on school days (L), expensive fertilizer (FZ), veterinary service (VS), bad debt (BD), customer relation (CR), credit (C), health hazards (HH), unfinished products (UP) and patronage $(\mathrm{P})$.

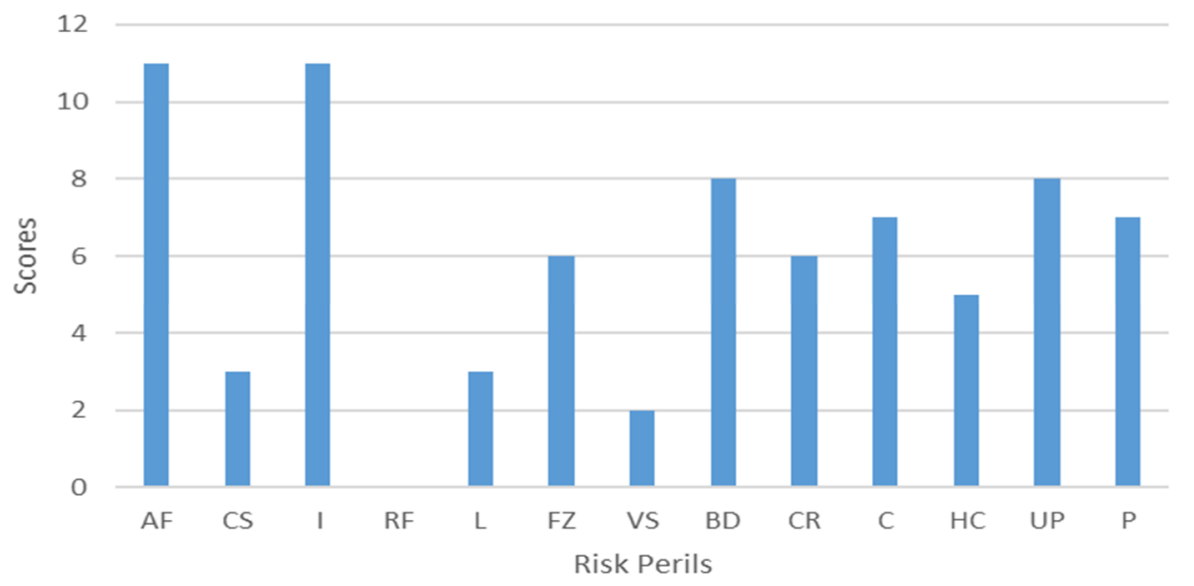

FIGURE 4.7: General Exposition Chart of Risks associated with all the SMEs Source: Field Data (2019)

\subsection{FURTHER ANALYSIS}

Data obtained from the financial institutions shows that SME's are not able to access finances easily due to the following risks associated with financing them; Default in loans repayment, Lack of managerial skills, and Misdirection of loan amount.

\section{Variables:}

A- Default in repayment

B- Lack of managerial skills

C- Misdirection of loan amount.

D- Mismanagement of loan

The above variables were used as indicators for chi-square test of the risk of financing SME's.

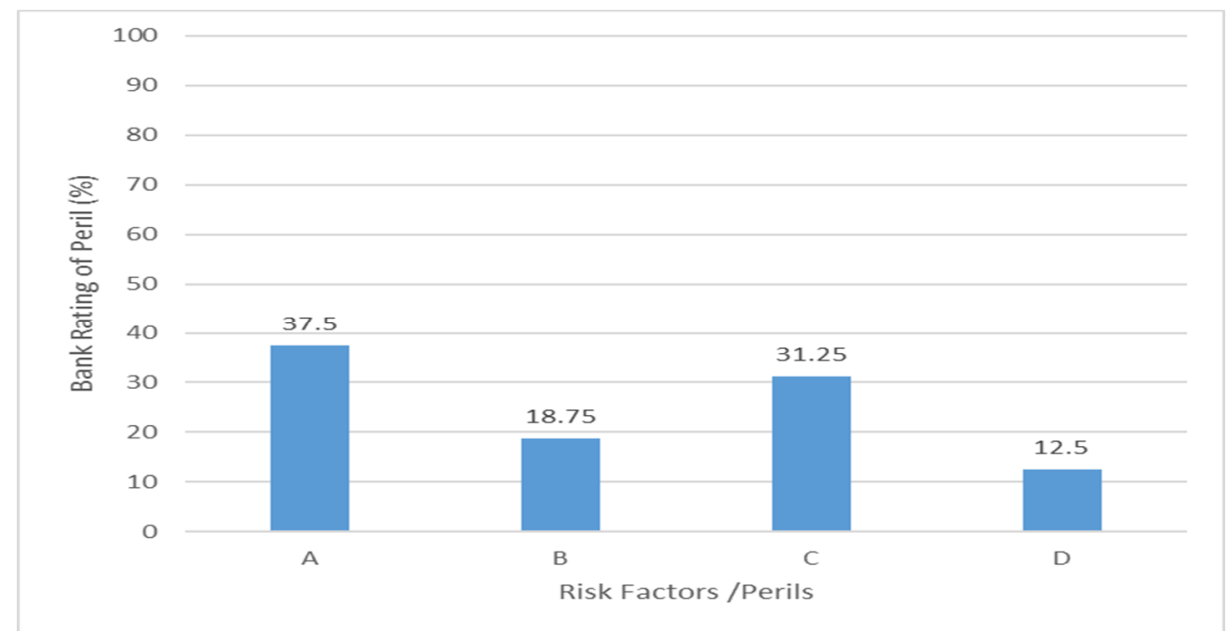

FIGURE 4.8: Banks’ Perceived Risks of Financing SMEs

Source: Field Data (2019)

From Figure 4.8, most of the sampled financial institutions (37.5\%) fail to grant loans to SME's due to default in repayment, $18.75 \%$ based on lack of managerial skills, $31.25 \%$ due to misdirection of loans and $12.5 \%$ based on mismanagement of loans. Deducing from the chart, there is every indication that the misapplication/misdirection of the loans obtained from the banks is a major cause of the SMEs' failing to honour 
their repayment schedules. In the same vein, the absence of professionals in the management teams constitutes the fundamental weakness in running most SMEs. For this lack of skilful management, the entrepreneurs are able to force their ways through to misappropriate the business resources in breach of the entity concept where the business resources must be kept separate from that of the proprietor.

Having deduced this from figure 4.8 , it has become necessary to statistically find out if these risk perils truly influences / cause the reluctance of the Banks to finance SMEs.

\subsection{CHI-SQUARE TEST}

HYPOTHESIS

$\mathrm{H}_{0}$ : All risks do contribute equally to SMEs' lack of finance

$\mathrm{H}_{1}$ : All risks do not contribute equally to SMEs' lack of finance

The statistic for the chi-square is stated as

$$
\chi^{2}=\sum_{1}^{4} \frac{(O-E)^{2}}{E}
$$

TABLE 12: CHI- SQUARE TABLE

\begin{tabular}{|l|l|l|l|l|l|}
\hline & $\mathrm{A}$ & $\mathrm{B}$ & $\mathrm{C}$ & $\mathrm{D}$ & TOTAL \\
\hline Observed (O) & 6 & 3 & 5 & 2 & 16 \\
\hline Probability & $1 / 4$ & $1 / 4$ & $1 / 4$ & $1 / 4$ & 1 \\
\hline $\mathrm{E}(\mathrm{x})(\mathrm{E})$ & 4 & 4 & 4 & 4 & 16 \\
\hline$(O-E)$ & 2 & -1 & 1 & -2 & 0 \\
\hline$(O-E)^{2}$ & 4 & 1 & 1 & 4 & 10 \\
\hline$\frac{(O-E) ? 2}{E}$ & 1 & $1 / 4$ & $1 / 4$ & 1 & 2.5 \\
\hline
\end{tabular}

$\chi^{2}=2.5$

$\chi_{(0.05)}^{2}=7.815$ at $\alpha=0.05$

Since $\chi^{2}=2.5<\chi_{(0.05)}^{2}=7.815$, we fail to reject null hypothesis $\left(\mathrm{H}_{\mathrm{o}}\right)$ that all the risks do contribute equally to SME's access to finance.

\subsection{DISCUSSION}

At $95 \%$ confidence interval, the chi-square test reveals that all the risks do contribute equally to SME's inability to access debt finance. This implies that each of the risk variables is sufficient to cause an SME loan application to be turn down. To this effect, a financial institution will refuse to grant loan to an SME applicant if one of the risk factors associated with debt financing criteria is present or active. Thus a bank will fail to grant a loan either due to high probability of: default to repay the loan or applicant has ever defaulted in the repayment of a previous loan; loan being misdirected, misapplied; or mismanaged. The applicant will equally be refused the loan if there is no evidence a skilful management team in the business. At any given time, any of these risks may result to the failure of the financial institutions to grant loans to an SME loan applicant. On evaluating these risks, out of the sixteen respondents from the financial institutions, majority of them $37.5 \%$ indicated a decline to grant the loan if applicant does not exhibit the capacity to repay as scheduled or has some traces of having defaulted in previous loans. The least considered peril that may result in the SME applicant not getting the loan is associated with the chances of the SME mismanaging the loan. This was voted for by $12.5 \%$ of the respondents.

\subsection{CONCLUSION AND RECOMMENDATIONS}

\subsection{CONCLUSION}

Small and medium-sized enterprises, undoubtedly plays a major role in creating jobs and maintaining economic dynamism. In Ghana, SME's are faced with a host of obstacles in their business activities. Primarily they have limited access to finance and therefore are mostly not able to engage skilful labour to manage or adopt the appropriate technologies improve operational efficiencies. They are vulnerable to most exogenous risk factors. They are neither able to build upon their strengths and take advantage of their operational opportunities nor work out to minimize their weakness.

Among these constraints, access to finance is the most serious peril for small business enterprises. Banks channel few funds to SME's. This is because most of the SMEs are not able to meet their lending criteria of evidence of ability to repay, effective and skilful management team, ability to appropriately apply and manage the loan efficiently. 


\subsubsection{RISKS OF SMEs}

At the end of this study the various financial risks of SME's identified include; Access to finance, Inflation and Bad debt. Access to finance and inflation are the most disturbing perils to the SMEs. Aside from not getting debt funding to augment the working capital, the entrepreneurs are sometimes also trapped into unexpected price increases due to inflation. They will unknowingly sell their goods at the old price only to realize there is a rise in the prices and they will need to add from the previous savings to enable them get the same basket goods they use to buy.

\subsubsection{EVALUATION OF THE RISKS}

SMEs are not able to access debt financing from the banks because the banks fear that the loans that may be granted to the SMEs may not be repaid. This is because the bankers do not trust the business discipline of the SME operators such as effectively complying with any loan repayment schedule. Skilful human resources are necessary to enhance their operational effectiveness and efficiencies so that whatever funds that are added to the business will enhance it yielding capacity. Finally, entrepreneurs must begin to respect the entity concept by not redirecting the business funds for the private use but should at least allow the business to use its resources respond generate the profits for them.

\subsubsection{RISKS OF FINANCING SME'S}

A comparative analysis of risks of the various categories of SME's reveals that access to finance and inflation are the most critical risks of SME's since it causes much loss to the industries.

At 0.05 significance level (95\% confidence interval), the chi-square test reveals that, default in loans repayment, misdirection of loans, mismanagement of loans and lack of managerial skills contributes equally to SME's inability to access of loans. All these risks contribute a loss to the financial institutions since the loans if paid can be reinvested to earn more profit. Misdirection of loans, mismanagement of loans and lack of managerial skills which can leads to the collapse of the enterprise are all threats to the financing institutions.

\subsection{RECOMMENDATIONS}

- The study reveals that SME's lacks managerial skills. It is therefore recommended that they hire at least middle level skilful human resource to run their businesses. Alternatively, the financial institutions and/or the local government authorities through the national board for small scale industries can organize managerial training programs for the SME's in order to improve upon their management skills.

- To better appreciate the SMEs financial needs and develop an appropriate package to support them, the study recommends that the financial institutions should at least dedicate a staff to appraise the SMEs needs and propose the appropriate solutions rather than lumps them to other corporate clients.

- It is also recommended that government should do well to stabilise the economy so that inflation may not sore and wash off these SMEs capitals. Again a local industry support unit may be established to finance these SMEs if they run into cash trapped zone.

\section{REFERENCES}

1. Abhor, J. and Quartey, P. (2010) Issues in SME development in Ghana and South Africa. International research Journal of finance and economics. Issue 39, pp 218-228

2. Adu Pandit, (2007). Research on SME Finance in Ghana. JICA, Ghana.

3. Alexander C. and Sheedy E. (2005). The Professional Risk Managers' Handbook: A Comprehensive Guide to Current Theory and Best Practices. PRMIA Publications. ISBN 0-9766097-0-3.

4. Altman E.I., and Saunders, A. (1997). Credit Risk Measurement: Developments over the last twenty Years, Journal of Banking and Finance, 21, 1721-1742.

5. Aryeetey E., Amoah B. N., Duggleby T., Hettige H., and Steel W. (1994). Supply and Demand for Small Enterprises in Ghana. Discussion Paper No. 251. Technical Department, Africa Region. Washington, D.C.: World Bank.

6. Asmelash B. (2002). Enhancing the Competitiveness and Productivity of Small and Medium Scale Enterprises (SMEs) in Africa: An Analysis of Differential Roles of National Governments through Improved Support Services.

7. Ayyagari, M. Demirgüç-Kunt, A. and Maksimovic, V. (2014) Who creates jobs in developing countries? Small business economics, 43(1), pp.75-99.

8. Beyene, A. (2000), 'Support services for enhancing competitiveness of African SMEs in regional and global markets: The Case of Namibia.

9. Berger, A.N. Rosen, R. J. and Udell, G. F. (2007) Does market size structure affect competition? The case of small business lending. Journal of Banking and Finance 31, 11-33.

10. Hubbard D. (2009) The Failure of Risk Management: Why It's Broken and How to Fix It pg. 46, John Wiley and Sons.

11. Duan Hongbo, Xiaojie Han and Hongbo Yang (2009). An Analysis of Causes for SMEs Financing Difficulty 
12. European Commission (2003), EC: SME Definition.

13. Fadeyibi I.O. (2009), SMEs and the Problem of financing in developing economy. (The case of Nigeria, West Africa), Partners in success: Strategic HR and Entrepreneurship Excel Book, India pp 695-704

14. Falker E. M., Hiebi M. R. W. (2014) Risk management in SMEs; a systematic review of available evidence. The Journal of Risk Finance vol.16 ISS,2 pp122-144.

15. Wenyan F. and Zonghua L., (2005), On the relationship between financing structure and governance structure.

16. Huang, Shaoa and Zhang, Gang (2007), Analysis of China's public companies' stock financing bias. Economic Studies

17. Ikasari, N; Sumransat, T; Eko, U and Kusumastuti, R (2016), "Access of Small and Medium Enterprises to Finance in Rural Areas: Case of Indonesia and Thailand", International Journal of Economics and Management Engineering, Vol. 10(5), pp 1661-1668.

18. ISO/IEC Guide, (2009), Risk management -- Vocabulary International Organization for Standardization.

19. Turner J. Rodney, Ledwith Ann, Kelly John (2009), Project management in small to medium-sized enterprises: A comparison between firms by size and industry. Volume 2. Pg 282-296.

20. Marcelino-Sádada, S. Perez-Ezcurdia, A. Echeverria Lazcano, A.M. and Villanueva, P (2014) Project risk management methodology for small firms

21. Mensah Sam,(2004) A review of SME financing schemes in Ghana International Journal of project management vol 32 no. 2 pp327-340

22. Petrakis P.E., Kostis P.C. (2012), The Role of Knowledge and Trust in SMEs, Journal of the Knowledge Economy, DOI: 10.1007/s13132-012-0115-6. (accessed $29^{\text {th }}$ June 2020)

23. Rajeevan, N. Suphey, M. M. and Rajasekar, S. (2015) The critical role of micro, small and medium enterprises in employment generation; An Indian experience. Asian social science, 11(24), pp 258-267.

24. World Bank (2006). World Bank Supports Ghana: Micro, Small and Medium Enterprises (MSME) Development, World Bank (Washington, DC), Press Release - January, 2006.

APPENDIX 1: TABLES

TABLE 1: PAIR-WISE RANKING OF THE RISKS OF TRADING AND TEXTILES

\begin{tabular}{|l|l|l|l|l|l|l|}
\hline & BD & CR & AF & C & CS & I \\
\hline BD & - & CR & AF & BD & BD & I \\
\hline CR & & - & AF & CR & CR & I \\
\hline AF & & & - & AF & AF & I \\
\hline $\mathbf{C}$ & & & & - & C & I \\
\hline CS & & & & & - & I \\
\hline I & & & & & & - \\
\hline
\end{tabular}

TABLE 2: Pair-wise ranking of Trading and Agriculture.

\begin{tabular}{|l|l|l|l|l|l|l|l|}
\hline & FP & RF & L & FZ & VS & CS & I \\
\hline FP & - & FP & FP & FZ & FP & FP & I \\
\hline F & & - & RF & FZ & RF & RF & I \\
\hline L & & & - & FZ & L & L & I \\
\hline FZ & & & & - & FZ & CS & I \\
\hline VS & & & & & - & VS & VS \\
\hline CS & & & & & & - & CS \\
\hline I & & & & & & & - \\
\hline
\end{tabular}

TABLE 1.1: SCORE OF TRADING AND TEXTILE INDUSTRY

\begin{tabular}{|l|l|}
\hline RISK & SCORE \\
\hline BD & $\mathbf{2}$ \\
\hline CR & $\mathbf{3}$ \\
\hline AF & $\mathbf{4}$ \\
\hline C & $\mathbf{1}$ \\
\hline CS & $\mathbf{0}$ \\
\hline I & $\mathbf{5}$ \\
\hline
\end{tabular}

Table 2.1: Scores of Trading and Agriculture.

\begin{tabular}{|l|l|}
\hline RISK & SCORE \\
\hline FP & 4 \\
\hline RF & 3 \\
\hline L & 2 \\
\hline FZ & 4 \\
\hline VS & 2 \\
\hline CS & 2 \\
\hline I & 4 \\
\hline
\end{tabular}


TABLE 3: RANKING THE RISKS OF TRADING WITH THE AGRO PROCESSING INDUSTRY

\begin{tabular}{|l|l|l|l|l|l|l|l|}
\hline & HP & UP & CR & AF & P & CS & I \\
\hline HP & - & UP & CR & AF & P & CS & I \\
\hline UP & & - & UP & AF & P & CS & I \\
\hline CR & & & - & AF & CR & CR & I \\
\hline AF & & & & - & AF & AF & I \\
\hline P & & & & & - & P & I \\
\hline CS & & & & & & - & CS \\
\hline I & & & & & & & - \\
\hline
\end{tabular}

TABLE 4: RANKING THE RISKS OF AGRICULTURAL INDUSTRY WITH THE TEXTILE INDUSTRY

\begin{tabular}{|l|l|l|l|l|l|l|l|l|}
\hline RISK & AF & RF & L & FZ & VS & BD & CR & C \\
\hline AF & - & AF & AF & AF & AF & BD & AF & AF \\
\hline RF & & - & RF & RF & VS & BD & RF & C \\
\hline L & & & - & FZ & L & BD & CR & C \\
\hline FZ & & & & - & FZ & BD & CR & C \\
\hline VS & & & & & - & VS & VS & C \\
\hline BD & & & & & & - & BD & BD \\
\hline CR & & & & & & & - & CR \\
\hline C & & & & & & & & - \\
\hline
\end{tabular}

TABLE 5: RANKING OF THE RISKS OF AGRICULTURE INDUSTRY WITH AGRO PROCESSING INDUSTRY

\begin{tabular}{|l|l|l|l|l|l|l|l|l|l|}
\hline RISK & HP & UP & CR & AF & RF & L & FZ & VS & P \\
\hline HP & - & UP & HP & AF & RF & HP & FZ & VS & P \\
\hline UP & & - & UP & AF & RF & UP & UP & VS & P \\
\hline CR & & & - & AF & CR & L & FZ & CR & CR \\
\hline AF & & & & - & AF & AF & AF & AF & P \\
\hline RF & & & & & - & RF & FZ & RF & P \\
\hline L & & & & & & - & FZ & L & P \\
\hline FZ & & & & & & & - & VS & FZ \\
\hline VS & & & & & & & & - & VS \\
\hline P & & & & & & & & & - \\
\hline
\end{tabular}

TABLE 3.1: SCORE OF TRADING AND AGRO PROCESSING INDUSTRY

\begin{tabular}{|l|l|}
\hline RISKS & SCORE \\
\hline HP & 0 \\
\hline UP & 2 \\
\hline CR & 3 \\
\hline AF & 5 \\
\hline P & 3 \\
\hline CS & 3 \\
\hline I & 5 \\
\hline
\end{tabular}

TABLE 4.1: SCORE OF AGRIC. WITH THE TEXTILE INDUSTRY

\begin{tabular}{|l|l|}
\hline RISK & SCORE \\
\hline AF & 6 \\
\hline RF & 3 \\
\hline L & 1 \\
\hline FZ & 2 \\
\hline VS & 3 \\
\hline BD & 6 \\
\hline CR & 3 \\
\hline C & 4 \\
\hline
\end{tabular}

TABLE 5.1: SCORE OF AGRIC. WITH AGRO PROCESSING INDUSTRY

\begin{tabular}{|l|l|}
\hline RISKS & SCORE \\
\hline HP & 2 \\
\hline UP & 2 \\
\hline CR & 3 \\
\hline AF & 7 \\
\hline RF & 4 \\
\hline L & 2 \\
\hline FZ & 5 \\
\hline VS & 4 \\
\hline P & 5 \\
\hline
\end{tabular}


TABLE 6: RANKING OF RISKS OF TEXTILE

INDUSTRY WITH AGRO PROCESSING INDUSTRY
TABLE 6.1: SCORE OF TEXTILE

WITH AGRO PROCESSING INDUSTRY

\begin{tabular}{|l|l|l|l|l|l|l|l|l|l|l|}
\hline RISKS & BD & CR & AF & C & HC & UP & P & & RISKS & SCORE \\
\hline BD & - & BD & AF & BD & BD & UP & P & & BD & 3 \\
\hline CR & & - & AF & CR & HC & CR & P & & CR & 2 \\
\hline AF & & & - & AF & AF & UP & AF & & AF & 5 \\
\hline C & & & & - & C & UP & P & C & 1 \\
\hline HC & & & & & - & HC & P & & HC & 2 \\
\hline UP & & & & & & - & UP & & UP & 4 \\
\hline P & & & & & & & - & & P & 4 \\
\hline
\end{tabular}

TABLE 7: PAIR-WISE RANKING OF THE GENERAL RISKS ASSOCIATED WITH SME's

TABLE 7.1: SCORE OF THE

\begin{tabular}{|l|l|l|l|l|l|l|l|l|l|l|l|l|l|}
\hline Risks & AF & CS & I & RF & L & FZ & VS & BD & CR & C & HP & UP & P \\
\hline AF & - & AF & I & AF & AF & AF & AF & AF & AF & AF & AF & AF & AF \\
\hline CS & & - & I & CS & L & FZ & CS & BD & CR & C & CS & UP & P \\
\hline I & & & - & I & I & I & I & BD & I & I & I & I & I \\
\hline RF & & & & - & L & FZ & VS & BD & CR & C & HC & UP & P \\
\hline L & & & & & - & FZ & VS & BD & L & C & HC & UP & P \\
\hline FZ & & & & & & - & FZ & BD & CR & FZ & HC & FZ & P \\
\hline VS & & & & & & & - & BD & CR & C & VS & UP & P \\
\hline BD & & & & & & & & - & CR & C & BD & UP & BD \\
\hline CR & & & & & & & & & - & C & CR & UP & P \\
\hline C & & & & & & & & & & - & HC & C & P \\
\hline HC & & & & & & & & & & & - & UP & HC \\
\hline UP & & & & & & & & & & & & - & UP \\
\hline P & & & & & & & & & & & & & - \\
\hline
\end{tabular}

\begin{tabular}{|l|l|l|}
\hline Risks & SCORE & Rank \\
\hline AF & 11 & $1^{\text {st }}$ \\
\hline CS & 3 & $6^{\text {th }}$ \\
\hline I & 11 & $1^{\text {st }}$ \\
\hline RF & 0 & $8^{\text {th }}$ \\
\hline L & 3 & $6^{\text {th }}$ \\
\hline FZ & 6 & $4^{\text {th }}$ \\
\hline VS & 2 & $7^{\text {th }}$ \\
\hline BD & 8 & $2^{\text {nd }}$ \\
\hline CR & 6 & $4^{\text {th }}$ \\
\hline C & 7 & $3^{\text {rd }}$ \\
\hline HC & 5 & $5^{\text {th }}$ \\
\hline UP & 8 & $2^{\text {nd }}$ \\
\hline P & 7 & $3^{\text {rd }}$ \\
\hline
\end{tabular}

